\title{
AS MAIS VALIAS DA ABORDAGEM METODOLÓGICA MISTA: 0 CASO DO ESTUDO DO EFEITO DA PARTICIPAÇÃO NO FESTIVAL SUDOESTE NA CONSTRUÇÃO DA(S) IMAGEM(NS) SOBRE O DESTINO ALENTEJO LITORAL E NA INTENÇÃO DE REVISITA ${ }^{1}$
}

\author{
Sandra Saúde ${ }^{12}$ e Ana Isabel Rodrigues ${ }^{1}$ \\ 1 Instituto Politécnico de Beja, Portugal. ssaude@ipbeja.pt; ana.rodigues@ipbeja.pt; \\ ${ }^{2}$ CICS.NOVA - Centro Interdisciplinar de Ciências Sociais
}

\begin{abstract}
Resumo. Esta comunicação pretende caracterizar as mais valias do desenvolvimento de uma abordagem metodológica exploratória do tipo misto tendo por base o estudo do efeito que a participação no festival de música (MEO)Sudoeste, realizado em 2017, que teve/tem na(s) imagem(ns) construídas sobre a região Alentejo Litoral/Sudoeste e na(s) respetiva(s) intenção(ões) de revisita. A investigação permitiu: 1) identificar os perfis de imagem de destino (ID) construídos pelos festivaleiros pós festival; 2) aferir a opinião sobre o efeito induzido pela participação no festival sobre essa(s) ID e 3) tipificar as intenções de revisita e de recomendação de visita à região. A recolha e a análise combinada de dados de natureza quantitativa e qualitativa permitiu enriquecer a identificação e a caracterização dos perfis de imagem tidos pelos festivaleiros. Se os dados de natureza quantitativa situam os perfis tipo e a expressividade das respetivas dimensões, são os dados de natureza qualitativa que permitem apreender a sua verdadeira amplitude e significância. Os resultados evidenciam que por via da colheita e interpretação combinada de dados quantitativos e dados qualitativos, o método misto de pesquisa é o que assegura maior potencial e riqueza na triangulação e interpretação dos dados, sendo o mais adequado para objetos de estudo multidimensionais.
\end{abstract}

Palavras-chave: Método Misto de Pesquisa; Técnicas de Análise Qualitativa; Técnicas de Análise Quantitativa; Imagem de Destino; Festival (MEO)Sudoeste.

THE ADVANTAGES OF THE MIXED METHODS APPROACH: THE CASE STUDY OF THE PARTICIPATION EFFECT IN THE SUDOESTE FESTIVAL IN THE FORMATION OF THE DESTINATION IMAGE(S) ABOUT ALENTEJO LITORAL AND IN THE REVISITING INTENTION

\begin{abstract}
This paper intends to characterize the advantages of the development of an exploratory methodological approach of the mixed type based on the study of the effect that the participation in the music festival (MEO) Sudoeste, carried out in 2017, had/has in the image(s) formed over the Alentejo Litoral/Sudoeste region and in the respective intention(s) to revisit. The research allowed: 1) to identify the destination image (ID) profiles built by festivalgoers post-festival; 2) assess the opinion on the effect induced by participation in the festival on their ID and 3) typify the intentions of revisiting and of recommending visits to the region. The combined collection and analysis of data of a quantitative and qualitative nature made it possible to enrich the identification and characterization of ID profiles developed by festivalgoers. If the data of a quantitative nature situates the type profiles and the expressiveness of the respective dimensions, it is the data of a qualitative nature that allows to apprehend its true amplitude and significance. The results show that, through the combined collection and interpretation of quantitative and qualitative data, the mixed research method is the one that ensures greater potential and richness in triangulation and interpretation of the data, being the most suitable for multidimensional study objects.
\end{abstract}

Keywords: Mixed Methods Approach; Qualitative Analysis Techniques; Quantitative Analysis Techniques; Destination Image; (MEO) Sudoeste Festival.

${ }^{1}$ Este trabalho é financiado por fundos nacionais através da FCT - Fundação para a Ciência e a Tecnologia, I.P., no âmbito do projeto «UIDB/04647/2020» do CICS.NOVA - Centro Interdisciplinar de Ciências Sociais da Universidade Nova de Lisboa. 


\section{INTRODUÇÃO}

O ponto de partida do estudo efetuado e que a seguir se apresenta foi o estudo do impacte económico e sociocultural do festival de música (MEO)Sudoeste na região, em 2017, quando da comemoração do seu $20^{\circ}$ aniversário.

Entre os resultados apurados, destacou-se o efeito positivo do evento na divulgação e consolidação da imagem do território. Tendo por base esta conclusão, interessou, numa segunda fase do estudo, centrar a análise na caracterização e compreensão do significado desse efeito junto dos festivaleiros, visitantes da região pela primeira vez quando da participação no festival. Em concreto, interessou-nos:

- caracterizar o impacte que a participação no festival, em 2017, teve/tem na(s) imagem(ns) construídas sobre a região: Alentejo Litoral/Sudoeste e na(s) respetiva(s) intenção(ões) de revisita.

Assumiram-se como dimensões chave da recolha de dados:

1. os atributos/as características que os festivaleiros associam à região, fruto da experiência tida resultante da participação no festival;

2. a intenção e a probabilidade de voltar a visita a região;

3. a recomendação de visita à região, dada, ou não, a amigos/familiares;

4. a opinião sobre se a ida ao (MEO)Sudoeste influenciou a imagem que passou a ter sobre a região e de que forma caracteriza a imagem que tem agora.

Dada a natureza multidimensional do objeto de estudo, optou-se pelo desenvolvimento de uma abordagem metodológica exploratória do tipo misto.

A abordagem metodológica seguida é plenamente justificada pelas questões base de investigação, bem como, pela necessidade de complementar dados de caracterização, de perfil mais quantitativo, e de interpretação/justificação contextualizada, de perfil qualitativo.

Tendo por base o estudo desenvolvido, pretende-se com esta comunicação refletir sobre as mais-valias do uso do método misto de pesquisa para o enriquecimento e a compreensão sustentada dos resultados de um processo de investigação social. 


\section{A MULTIDIMENSIONALIDADE DO CONCEITO IMAGEM DE DESTINO (ID)}

\subsection{ID e a intenção de revisita}

A imagem de um destino, na perspetiva da oferta ou procura, assume-se como com conceito valioso quer na estratégia de posicionamento de destino (Pike \& Ryan, 2004), quer no processo de seleção de destinos e, por essa razão, tem recebido atenção substancial dos investigadores desde a década de 1970 (e.g. Gallarza, Saura \& Garcia, 2002). Ao examinar algumas das definições de DI, torna-se evidente que se trata de um conceito amplo, eclético e abrangente. Crompton (1979) propôs uma das definições mais citadas, enfatizando o fato de que a imagem é uma soma de múltiplos elementos, como crenças, ideias e impressões sobre um destino. O pensamento de Crompton (1979) foi estendido por Phelps (1986), que também a definiu com base em impressões e percepções; Gartner (1989) para quem a imagem de destino é uma "combinação complexa". Esses breves exemplos mostram a multimensionalidade e imprecisão deste construto. As imagens são consideradas, ao mesmo tempo, percepções, impressões ou sensações sobre diferentes atributos de um destino. Por esta razão, Rodrigues, Correia \& Kozak (2012) advogam que DI assume-se como um "constructo chapéu" [umbrella construct], uma vez que: (i) são conceitos baseados numa combinação de elementos que ajudam a organizar um corpo de conhecimentos em torno de um tópico; (ii) o progresso do conceito assenta na dialética entre relevância e rigor, abertura e disciplina, conceptualização e operacionalização; (iii) são conceitos unificadores entre os investigadores, a fim de organizar um campo de conhecimento.

É esta riqueza multidimensional que faz com que a ID seja uma variável fundamental na definição de estratégias de marketing de destinos, sobretudo porque têm consequências diretas em variáveis como a satisfação sentida pelo turista ou a lealdade ao destino turístico, como vários estudos já o demonstraram (e.g. Bigné, Sanchez \& Sanchez, 2001). Informação prévia sobre o destino ou o facto de alguém já o ter visitado antes são factores que deverão ser tidos em consideração em estudos de ID, uma vez que podem causar diferentes opiniões. A par disso, sendo a ID um conceito multidimensional requere desta forma abordagens multidisciplinares (Rodrigues et al., 2012) que, por sua vez, necessita de formas de medição complementares (quanti_quali ou quali_quanti) como defendem alguns autores (Jenkins, 1999; entre outros). 


\section{AS MAIS VALIAS DAS ABORDAGENS METODOLÓGICAS MISTAS NA INVESTIGAÇÃO SOCIAL}

Produzir ciência e conhecimento científico no domínio das ciências sociais implica umbilicalmente a assunção de que somos produtores e produto da realidade que estudamos. Implica saber gerir essa dupla e simultânea condição de ser sujeito-investigador e de objeto-investigado; implica assumir uma postura de produtor de conhecimento e de, simultaneamente, beneficiário do processo de produção. A investigação em ciências sociais tende, pois, a ser sempre um trabalho de reelaboração, de reinterpretação de um conjunto de fenómenos que todos nós experienciamos. No domínio da relação sujeito-objeto de investigação, e do ponto de vista ontológico, epistemológico e metodológico é possível identificar um conjunto de paradigmas estruturantes que dominaram, nos últimos tempos, a forma de observar e de interpretar a realidade envolvente, isto é, a forma de fazer ciência.

$\mathrm{Na}$ linha do tempo, distingue-se, em primeiro lugar, a influência dominante da perspetiva positivista (e, depois, pós-positivista) que advoga a importância da procura da objetividade e das conclusões sustentadas em evidências factuais e mensuráveis. Numa segunda fase, evolui-se para a assunção da realidade como um objeto multidimensional, histórica e socialmente construído em que a sua compreensão implica interpretação e contextualização, sendo estes os pressupostos de base do construtivismo ou da perspetiva interpretativista. Para os defensores do paradigma emancipatório/ transformativo, a compreensão da realidade e das suas múltiplas características implica a análise contextualizada e crítica das suas causas societais e individuais (Mertens, 2005).

Cada um destes paradigmas constituem "sistemas de crenças e práticas que influenciam a forma como os investigadores selecionam tanto as questões que estudam como os métodos que usam para as estudar" (Morgan, 2007, p.51). Se a abordagem metodológica quantitativa é a que domina na perspetiva positivista (séc $X I X / i n i ́ c i o s$ séc $X X$ ) e póspositivista (último terço do séc XX), na matriz construtivista (a partir da primeira metade do século $\mathrm{XX)}$ é dado o primado ao método qualitativo de pesquisa e de análise.

A aposta na abordagem mista, isto é, o uso complementar de métodos e técnicas quanti/qualitativas e/ou quali/quantitativas só se consolida no final do século $\mathrm{XX}$ tendo por base, um "novo" modelo de referência teórico: o pragmático. "O paradigma pragmático "coloca" no centro o problema de investigação e faz recurso de todas as abordagens para o entender." (Creswell, 2003, p.11). "Colocando a questão de pesquisa como 'central', os 
métodos de recolha e análise de dados são escolhidos tendo em conta a maior probabilidade de fornecerem insights sobre a questão, não respeitando qualquer tipo de lealdade filosófica a qualquer paradigma alternativo" (Mackenzie \& Knipe, 2006, p. 5).

A defesa da necessidade de uma abordagem metodológica sustentada pela combinação coerente e holística dos procedimentos de pesquisa e de análise qualitativa e quantitativa (ou vice-versa) é justificada pela natureza multidimensional e interdependente dos problemas e objetivos de investigação. Creswell et al. (2003) definem o método misto (mixed method) como um procedimento metodológico de recolha e de análise de dados que combina técnicas quantitativas e qualitativas num mesmo desenho de pesquisa, enriquecendo, por via da triangulação e da interação, as possibilidades analíticas e as conclusões a obter.

Os métodos mistos sustentam-se na assunção de que, por um lado, não existe uma única e objetivável realidade e que, por outro lado, a sua interpretação e compreensão implicam contextualização e capacidade de triangulação de pontos de vista; implica intersubjectividade e abdução (Morgan, 2007), isto é, "a dialética complementar e constante entre o desenvolvimento teórico indutivo e dedutivo, e não a confiança absoluta num ou noutro."(Pearce, 2012, pp. 832-833).

O método misto difere da abordagem multimétodos (multimethods), na medida em que não se sobrepõem múltiplas formas quantitativas e qualitativas de recolha de dados. O método misto legitima-se e diferencia-se na assunção da natureza multidimensional do problema inicial em investigação que justifica ontológica, epistemológica e metodologicamente uma abordagem que garanta a recolha (sequencial ou simultânea), a análise e a integração interpretativa de dados qualitativos e quantitativos (ou vice-versa) (Creswell, 2015).

Face à natureza multidimensional do conceito de imagem de destino (ID), a opção pela abordagem metodológica a seguir, para o estudo do efeito da participação no festival (MEO)Sudoeste nas imagens construídas sobre a região Alentejo Litoral/Sudoeste, teria que necessariamente recair pelo método misto. Esta escolha também se fundamenta na evolução registada, particularmente nas últimas décadas, nos procedimentos seguidos para avaliação de ID em que são aplicadas e combinadas formas de medição mais holísticas e qualitativas, assentes em questionamentos de natureza aberta (usando técnicas como a "Elicitação Livre de Palavras" (Coshall, 2000, entre outras), e escalas de medição de natureza quantitativa e fechada, como a proposta por Beerli e Martin (2004). 


\section{METODOLOGIA}

\subsection{Objetivo e questões orientadoras do estudo}

O objetivo central do estudo desenvolvido foi o de caracterizar o impacte que a participação no festival (MEO)Sudoeste, em 2017, teve/tem na(s) imagem(ns) construídas e na(s) intenção(ões) de revisita partilhadas pelos festivaleiros acerca do destino turístico: Alentejo Litoral/Sudoeste.

Assumiram-se como questões orientadoras do estudo (Qo), as seguintes:

- Q01: Quais os atributos que os festivaleiros associam à região Sudoeste/Alentejo Litoral?

- Qo2: Qual a intenção e a probabilidade de voltar a visita a região manifestadas pelos festivaleiros?

- Qo3: Será que os festivaleiros já recomendaram a visita à região a amigos e/ou familiares, após a sua estadia na região?

- Qo4: Será que a participação no festival influenciou a imagem que os festivaleiros passaram a ter sobre a região? Qo4.1: Se Sim, qual a imagem que passaram a ter?

- Qo5: Para os festivaleiros, quais são as três características que tornam a região única e diferente de todos os outros locais que visitaram até ao momento em Portugal?

As cinco dimensões de análise do estudo foram operacionalizadas através de indicadores que estruturam e fazem parte do inquérito por questionário aplicado via online. No total, o instrumento de recolha de dados tem oito perguntas sendo as seis primeiras de natureza fechada, de resposta única, em escala do tipo Likert ou de opção: Sim/Não e as duas últimas, de natureza aberta. O questionário foi previamente validado por um painel de especialistas. A fiabilidade das duas escalas de Likert utilizadas foi comprovada via alfa de Cronbach $(0,856$ e 0,839 , respetivamente).

O questionário aplicado, tem ao início uma pergunta de seleção, a fim de identificar se o respondente já tinha, ou não, estado na região antes da ida ao (MEO)Sudoeste, em 2017. Apenas avançaram para as questões seguintes, os que assumiram ter estado pela primeira vez no território aquando da edição de 2017 do festival; assegurou-se por esta via que as 
suas impressões, opiniões e imagens foram apenas influenciadas por essa experiência (Saúde \& Rodrigues, 2020).

\subsection{Técnica de recolha de dados e participantes no estudo}

O questionário foi enviado, entre 15 e 30 de junho de 2018, por email, a 231 festivaleiros, correspondente aos que tinham dado prévia autorização para serem contactados após a sua estadia no festival em 2017. Garantiu-se uma taxa de retorno de 53\%, equivalente a 122 respondentes: 100 de nacionalidade portuguesa e 22 estrangeiros A representatividade desta amostra a posteriori foi comprovada estatisticamente tendo por base as características do conjunto de festivaleiros inquiridos em 2017 (Saúde \& Rodrigues, 2020).

\subsection{Técnicas de análise de dados: procedimentos de análise quantitativa e qualitativa}

Os dados recolhidos através das seis questões de natureza quantitativa foram analisados através de estatística descritiva com apoio do software SPSS, versão 25 . Através da análise estatística determinou-se o perfil tipo sobre: 1) atributos associados à região Alentejo Litoral/Sudoeste; 2) intenção e probabilidade de revisita futura à região; 3) recomendação já dada a familiares/amigos para visitar o território e 4) opinião sobre se a imagem que passou a ter sobre a região foi influenciada pela ida ao festival.

As respostas dadas às duas perguntas abertas foram analisadas através da utilização combinada e complementar de dois CAQDAS (Computer Assisted/Aided Qualitative Data Analysis Software), a saber:

- $1^{\circ}$ momento: Utilização do CAQDAS T-LAB com o objetivo de realizar uma análise exploratória do corpus, extraindo as primeiras ideias, procurando perceber a relação entre palavras e palavras-chave.

- $\underline{2}^{\circ}$ momento: Utilização do webQDA com o objetivo de organizar e sistematizar o pensamento resultante da fase anterior, tendo por base uma análise dedutiva, baseada em dimensões de perceção e imagem (...) proveniente da fase de revisão de literatura. Foi feita a fase de codificação e interpretação, seguindo o método dedutivo. (...) Ao total, e para cada pergunta aberta, foram recolhidas 122 respostas ou unidades sintáticas, correspondentes cada uma à resposta dada à pergunta por cada inquirido (Saúde \& Rodrigues, 2020, p.244). 
A análise qualitativa permitiu caracterizar melhor as dimensões estruturantes das imagens partilhadas e construídas pelos festivaleiros sobre o território.

Em suma, desenvolveu-se uma abordagem metodológica mista, de natureza exploratória, que combinou a recolha e análise simultânea de dados quantitativos e qualitativos.

\section{O EFEITO DA PARTICIPAÇÃO NO FESTIVAL (MEO) SUDOESTE NA CONSTRUÇÃO DA(S) IMAGEM(NS) SOBRE O DESTINO ALENTEJO LITORAL/SUDOESTE E NA INTENÇÃO DE REVISITA}

\subsection{As imagens tidas sobre a região}

Entre os atributos que mais caracterizam a região (Figura1), os festivaleiros destacam:

1) ter boas praias $(64,8 \%$ concorda totalmente e $31,1 \%$ concorda);

2) transmitir uma sensação de fuga à rotina $(57,4 \%$ concorda totalmente e $42,6 \%$ concorda);

3) predominar um sentimento de autenticidade e genuinidade $(55,7 \%$ concorda totalmente e $44,3 \%$ concorda) e

4) ter uma paisagem bonita e atrativa (59,0\% concorda totalmente e $36,9 \%$ concorda).

Por oposição, discordam, particularmente, que o território:

1) esteja bem sinalizado ( $32,0 \%$ discorda totalmente e $41,8 \%$ discorda);

2) tenha boas acessibilidades (32,0\% discorda totalmente e $34,4 \%$ discorda);

3) tenha uma boa rede de supermercados/minimercados de vizinhança ( $16,4 \%$ discorda totalmente e $38,5 \%$ discorda) e

4) disponha de bons snack-bares/restaurantes (17,2\% discorda totalmente e $31,1 \%$ discorda). 


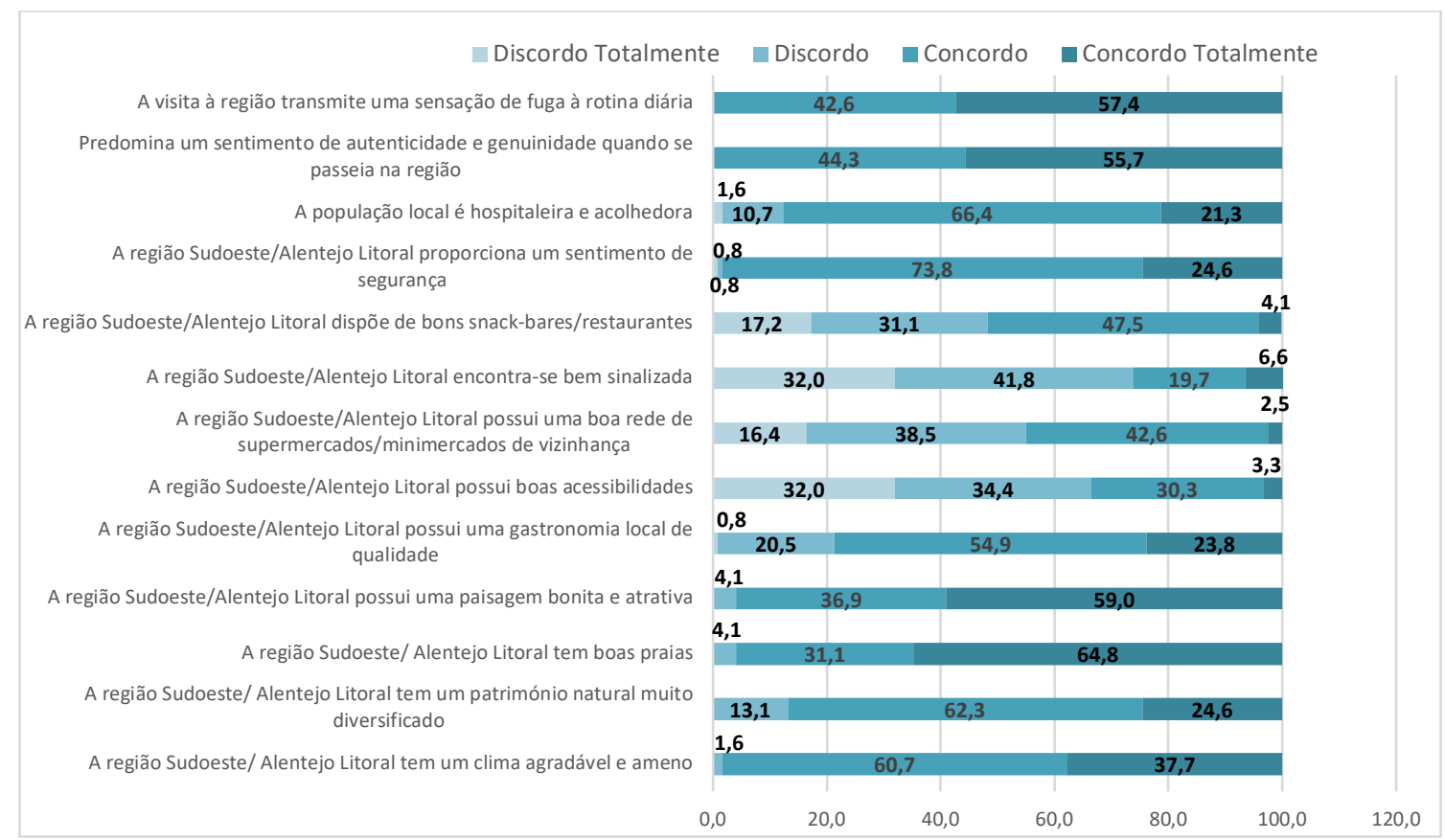

Figura 1. Atributos de imagem associados pelos festivaleiros à região (em \%) Fonte: SPSS, questionário aplicado em julho 2018.

Em síntese, são os atributos naturais e da atmosfera do lugar os mais valorizados.

Para a identificação destes atributos muito contribuiu a experiência de participação no (MEO)SUDOESTE, em 2017; 85,2\% dos festivaleiros assume que passou a ter uma imagem diferente e mais positiva da região após essa experiência. Dessa "nova" imagem fazem parte palavras-chave como: "praias"; "gostar"; "ótimo/ótima/ótimas"; "bonito/bonita/bonitas"; "animação/diversão"; "bom/boas" e "meosudoeste"; são estes os lemas $^{2}$ que mais se repetem nas unidades de texto analisadas. Entre as palavras-chave mais frequentes é evidente a "centralidade" de "praias" em torno da qual os lemas se associam de forma mais expressiva, tal como visível na Figura 2.

\footnotetext{
${ }^{2}$ Rótulos atribuídos a grupos de unidades lexicais classificadas de acordo com critérios linguísticos (lematização) (Manual T-LAB PLUS, 2019, disponível em: https://tlab.it/en/allegati/help en online ).
} 


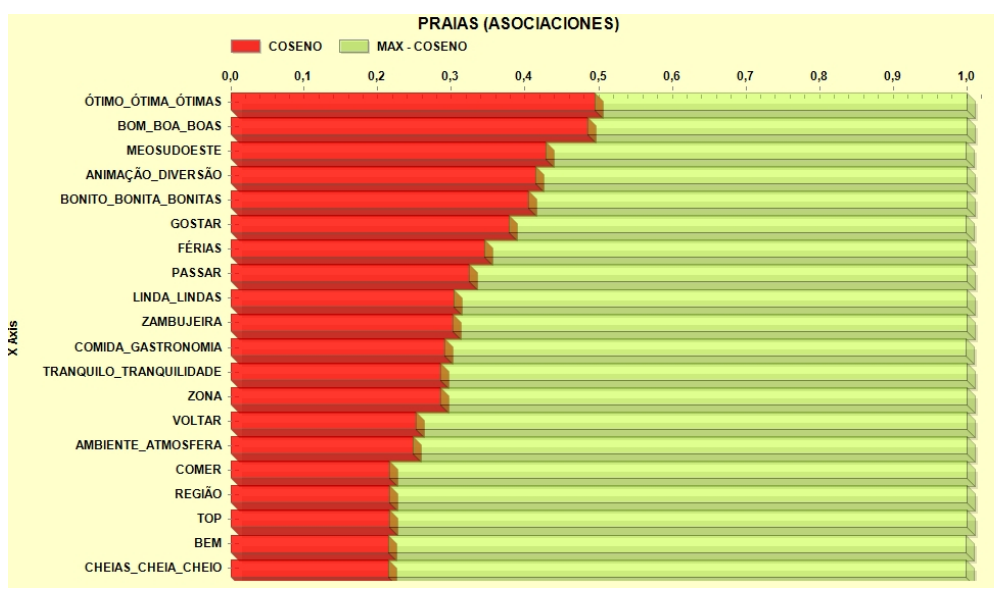

Figura 2. Associação dos lemas com a palavra-chave: praias

Legenda: COEF: Coeficiente de Associação entre o Lema "Praias" e os outros lemas. O índice de associação varia entre 0 e 1.

Fonte: T-LAB 2019, questionário aplicado em julho 2018 (Saúde \& Rodrigues, 2020, p. 245)

São também os elementos naturais (praias, natureza, pôr do sol, sol) e a atmosfera do lugar (associada a animação, diversão, meosudoeste) os atributos de imagem mais referenciados para justificar o carácter único e diferente da região face a outros locais visitados em Portugal (Tabela 1).

Tabela 1. Lemas/palavras-chave mais identificadas na elicitação livre sobre as 3 características que distinguem a região

\begin{tabular}{|c|c|c|c|}
\hline LEMAS & No de ocorrências & LEMAS & No de ocorrências \\
\hline PRAIA_PRAIAS & 105 & BONITA_BONITAS & 7 \\
\hline NATUREZA & 34 & ZAMBUJEIRA & 7 \\
\hline PORDOSOL & 30 & DIFERENTE & 5 \\
\hline ANIMAÇÃO & 27 & FÉRIAS & 5 \\
\hline BOA_BOAS_BOM & 24 & ALGARVE & 4 \\
\hline SOL & 19 & CANAL & 4 \\
\hline COMIDA_GASTRONOMIA & 16 & CLIMA & 4 \\
\hline MEOSUDOESTE & 14 & LINDA_LINDÍSSIMAS_LINDO & 4 \\
\hline DIVERSÃO & 13 & MAR & 4 \\
\hline AMBIENTE & 10 & MÚSICA & 4 \\
\hline ÓTIMA_ÓTIMO_ÓTIMAS & 10 & PAISAGEM & 4 \\
\hline
\end{tabular}

Fonte: T-LAB 2019, questionário aplicado em julho 2018 (Saúde \& Rodrigues, 2020, p.249)

Ao explorar e analisar de forma mais detalhada, com recurso ao webQDA, as respostas dadas pelos festivaleiros, foi possível ainda concluir que entre os aspetos que os festivaleiros menos gostaram da experiência na região destacam-se: 
- as experiências vivenciadas em certos cafés e espaços de restauração: Ref25 "nos cafés não se conseguia comer, rejeitavam a nossa presença e não nos ligavam nenhuma";

- a confusão e o excesso de pessoas em determinados locais de apoio: Ref2 "cafés sempre muito cheios, difícil de arranjar um lugar para comer";

- a necessidade de mais oferta de alojamento: Ref7 "poderia ter mais oferta de alojamentos para jovens";

- a dificuldade em chegar ao local, por falta de transportes públicos e sinalética: Ref2 "Não foi tudo bom, chegar ao sudoeste foi difícil, não há transportes" (Saúde \& Rodrigues, 2020).

Tendo por base as palavras-chave identificadas com o T-LAB cruzada com a análise categorial efetuada com o webQDA foi possível identificar que as imagens identificadas pelos festivaleiros do (MEO)Sudoeste são muito centradas no "recurso natural" predominante de que existem boas, bonitas e/ou ótimas praias. Há elementos distintivos associados à identidade turística e sociocultural do território que os jovens não destacam sendo por isso de classificar as imagens contruídas como incompletas e muito influenciadas/condicionadas pela relação muito específica e esporádica que o evento "permite" que os festivaleiros tenham com o território fora do recinto do festival (Saúde \& Rodrigues, 2020). A maior parte do tempo os festivaleiros estão no recinto do festival, com saídas quase exclusivas à localidade próxima de Zambujeira do Mar. O efeito positivo da participação no festival sobre as imagens construídas sobre a região é comprovado, no entanto, a análise mais detalhada sobre as características dessas imagens leva-nos a concluir que as mesmas incluem uma visão incompleta do território.

\subsection{A intenção e a probabilidade de revisitar a região}

Sobre a intenção de revisitar o Alentejo Litoral/Sudoeste, a grande maioria dos inquiridos assume que:

1) gostaria de voltar para visitar e/ou passar férias (88,5\% concorda e $9,0 \%$ concorda totalmente) e/ou

2) continuará a visitar e/ou passar férias, se tiver oportunidade $(77,0 \%$ concorda e $6,6 \%$ concorda totalmente). 


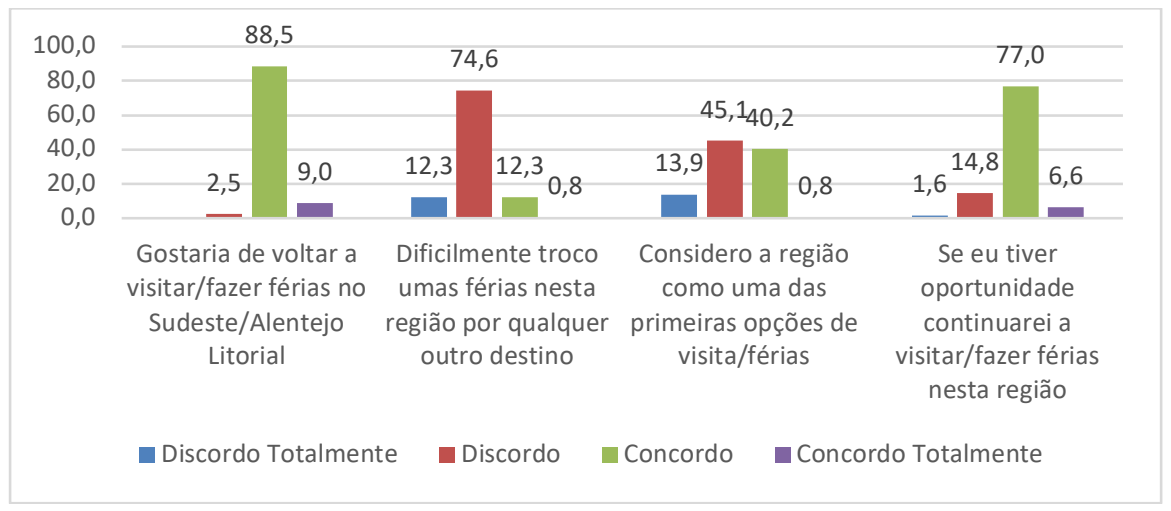

Figura 3. Intenção de voltar a visitar a região (em \%)

Fonte: SPSS, questionário aplicado em julho 2018.

$41 \%(40,8 \%+0,2 \%)$ assume que considera a região como uma das primeiras opções de visita e/ou de férias no futuro, embora a grande maioria 88,9\% $(74,6 \%+12,3 \%)$ discorde da dificuldade em trocar umas férias neste destino por outro (Figura 3).

Em termos de probabilidade de retorno ao destino, o valor médio é de 4,08 numa escala de 1: nada provável a 5: muito provável. Entre os inquiridos constata-se, adicionalmente, que $30,3 \%$ já voltou a visitar a região após a participação no festival (Fonte: SPSS, questionário aplicado em julho 2018).

Em síntese, verifica-se que a intenção e a probabilidade de revisita é bastante expressivo entre os festivaleiros que conheceram a região pela primeira vez aquando da edição de 2017 do festival.

\subsection{A recomendação de visita à região}

No que respeita à recomendação de visita dada a familiares e/ou amigos (Figura 4), 95,9\% assume concordar (90,2\% concorda e 5,7\% concorda totalmente) com a hipótese de o fazer e $97,5 \%$ (78,7\% concorda e $18,9 \%$ concorda totalmente) com a ideia de transmitir opiniões/sentimentos positivos sobre a região (Figura 5). Desde que esteve no festival em 2017, e no espaço de um ano, 44,3\% dos festivaleiros afirma que familiares e/ou amigos seus já visitaram a região fruto da sua recomendação (Fonte: SPSS, questionário aplicado em julho 2018). 


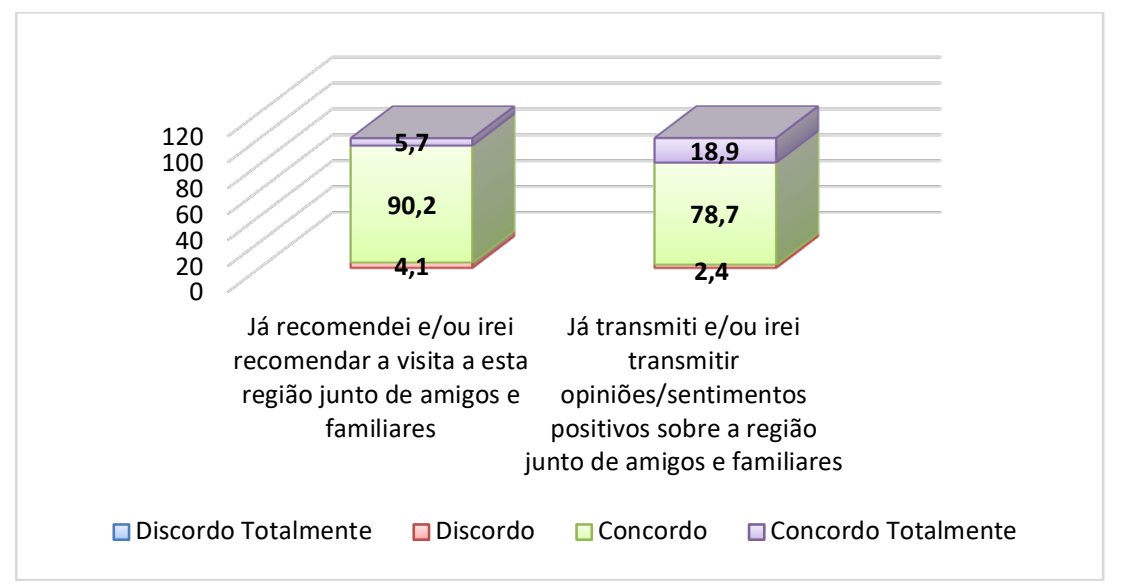

Figura 4. Recomendação de visita à região (em \%)

Fonte: SPSS, questionário aplicado em julho 2018.

\section{CONCLUSÕES}

O estudo efetuado permitiu identificar quais as dimensões estruturantes das imagens tidas pelos festivaleiros sobre a região Alentejo Litoral/Sudoeste, após um ano da sua primeira visita ao território em resultado da participação no festival de música (MEO)Sudoeste. Em termos globais, é uma imagem bastante positiva e diferente para melhor da partilhada antes do festival. Para os festivaleiros, os principais atributos da região são as suas ótimas praias, lindo por-do-sol, natureza e paisagem bonita e genuína. Também é destacada a atmosfera do lugar sendo valorizada a animação e o ambiente de diversão vivido por inerência da realização do próprio festival. Relativamente à possibilidade de revisita, a maioria dos inquiridos revela que tenciona voltar para visitar e/ou para passar férias, sendo que um terço já concretizou essa intenção. Fruto da imagem positiva tida, é também maioritário o grupo de festivaleiros que assume que já recomendou e/ou irá recomendar a amigos/familiares a visita ao Alentejo Litoral.

A recolha e a análise combinada de dados de natureza quantitativa e qualitativa permitiu enriquecer a identificação e a caracterização dos perfis de imagem tidos pelos festivaleiros. Se os dados de natureza quantitativa situam os perfis tipo e a expressividade das respetivas dimensões estruturantes (de acordo com a classificação utilizada de Beerli e Martin, 2004), são os dados de natureza qualitativa que permitem apreender a sua verdadeira amplitude e significância. Se ficássemos apenas com a análise da expressividade quantitativa dos atributos de imagem iriamos concluir que se destacam particularmente três: os recursos naturais, a atmosfera do lugar e o ambiente natural, concordantes com a imagem de marca da região, mas não conseguiríamos deduzir o carácter incompleto e condicionado das 
imagens tidas. Na realidade, ao explorar as narrativas dos festivaleiros sobre as características principais das imagens tidas sobre o território conclui-se que se centram e afunilam excessivamente nos elementos praia, por-do-sol, natureza e animação/meosudoeste. São imagens das quais emanam sensações positivas e que influem na intenção de revisita partilhada pela maioria, mas que, também, traduzem uma visão incompleta da região e excessivamente alinhada com as imagens exploradas pelo marketing do evento.

Quer por via de procedimento concomitante ou sequencial de recolha e análise de dados, quer por via da colheita e interpretação de dados quantitativos em primeiro lugar seguida dos qualitativos, ou vice-versa, o método misto de pesquisa é o que assegura maior potencial de triangulação e de enriquecimento mútuo de dados e perspetivas sendo o mais adequado para objetos de estudo multidimensionais.

\section{REFERÊNCIAS}

Beerli A. \& Martín J. D. (2004). Factors influencing destination image. Annals of Tourism Research, 31 (3), 657 681.

Bigné, E., Sanchez, M. I. \& Sanchez, J. (2001). Tourism image, evaluation variables and after purchase behaviour: Inter-relationship. Tourism Management, 22, 607-616.

Creswell, J.W. (2003). Research design: Qualitative, quantitative, and mixed methods approaches. (2nd ed.) Thousand Oaks: Sage.

Creswell, J.W., Plano Clark, V.L., Gutmann, M.L. \& Hanson, W.E. (2003). Advanced mixed methods research designs (209-240). In: Tashakkori, A., Teddie, C. (eds.) Handbook of Mixed Methods in Social \& Behavioral Research. Sage, Thousand Oaks.

Creswell, J. W. (2015). A Concise Introduction to Mixed Methods Research. Thousand Oaks: Sage.

Coshall, J. T. (2000). Measurement of tourists' images: The repertory grid approach. Journal of Travel Research, 39, 85-89.

Crompton, J. L. (1979). An assessment of the image of Mexico as a vacation and the influence of geographical location upon that image. Journal of Travel Research, 17 (4), 18-23.

Gallarza, G., Saura G. \& Garcia, H. (2002). Destination image: towards a conceptual framework. Annals of Tourism Research, 29 (1), 56-78.

Jenkins, O. H. (1999). Understanding and measuring tourist destination images. International Journal of Tourism Research, 1, 1-15.

Mackenzie, N. \& Knipe, S. (2006). Research dilemmas: Paradigms, methods and methodology. Issues in Educational Research, 16(2), 1-13.

Mertens, D.M. (2005). Research methods in education and psychology: Integrating diversity with quantitative and qualitative approaches ( $2^{\text {nd }}$ Edition). Thousand Oaks: Sage. 
Morgan, D. (2007). Paradigms Lost and Pragmatism Regained. Methodological Implications of Combining Qualitative and Quantitative Methods. Journal of Mixed Methods Research, 1 (1), 48-76.

Pearce, L.D. (2012). Mixed Methods Inquiry in Sociology. American Behavioral Scientist, 56(6), 829-848

Pike, S. \& Ryan, C. (2004). Destination positioning analysis through a comparison of cognitive, affective, and conative perceptions. Journal of Travel Research, 42 (May), 333-342.

Rodrigues, A., Correia, A. \& Kozak, M. (2012). Exploring the life-cycle model applied to 'umbrella constructs': destination image as an example. Tourism Recreation Research, 37 (2), 133-143.

Saúde, S. \& Rodrigues, A. I. (2020). Destination image(s) formed of the Alentejo Litoral/Southwest region from the experience of participating in the MEOSUDOESTE music festival (239-252). In: Costa, A.P., Reis, L. P., Moreira, A. (Ed.). Computer Supported Qualitative Research. Springer: Book series: Advances in Intelligent Systems and Computing. https://doi.org/10.1007/978-3-030-31787-4

Sedas Nunes, A. (1984). Questões Preliminares Sobre as Ciências Sociais. Vila da Feira: Editorial Presença, Lda. 